Portland State University

PDXScholar

TREC Final Reports

Transportation Research and Education Center

(TREC)

$4-2021$

\title{
The Impact of Ride Hail Services on the Accessibility of Nonprofit Services
}

Dyana P. Mason

University of Oregon

Miranda Menard

University of Oregon

Follow this and additional works at: https://pdxscholar.library.pdx.edu/trec_reports

Part of the Transportation Commons, Urban Studies Commons, and the Urban Studies and Planning Commons

Let us know how access to this document benefits you.

\section{Recommended Citation}

Mason, Dyana P. and Miranda Menard. The Impact of Ride Hail Services on the Accessibility of Nonprofit Services. NITC-RR-1357. Portland, OR: Transportation Research and Education Center (TREC), 2021. https://dx.doi.org/10.15760/trec.260

This Report is brought to you for free and open access. It has been accepted for inclusion in TREC Final Reports by an authorized administrator of PDXScholar. Please contact us if we can make this document more accessible: pdxscholar@pdx.edu. 

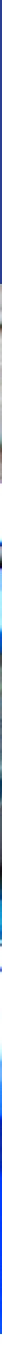

\title{
The Impact of Ride Hail Services on the Accessibility of Nonprofit Services
}

\author{
Dyana P. Mason, Ph.D.
}

Miranda Menard

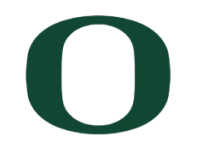




\title{
The Impact of Ride Hail Services on the Accessibility of Nonprofit Services
}

\author{
Final Report
}

\author{
NITC-SS-1357 \\ by \\ Dyana P. Mason \\ University of Oregon \\ Miranda Menard \\ University of Oregon
}

for

National Institute for Transportation and Communities (NITC)

P.O. Box 751

Portland, OR 97207
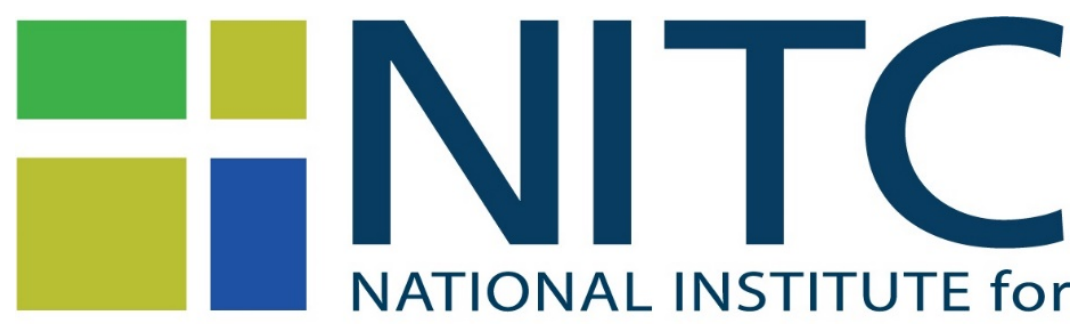

TRANSPORTATION and COMMUNITIES

April 2021 


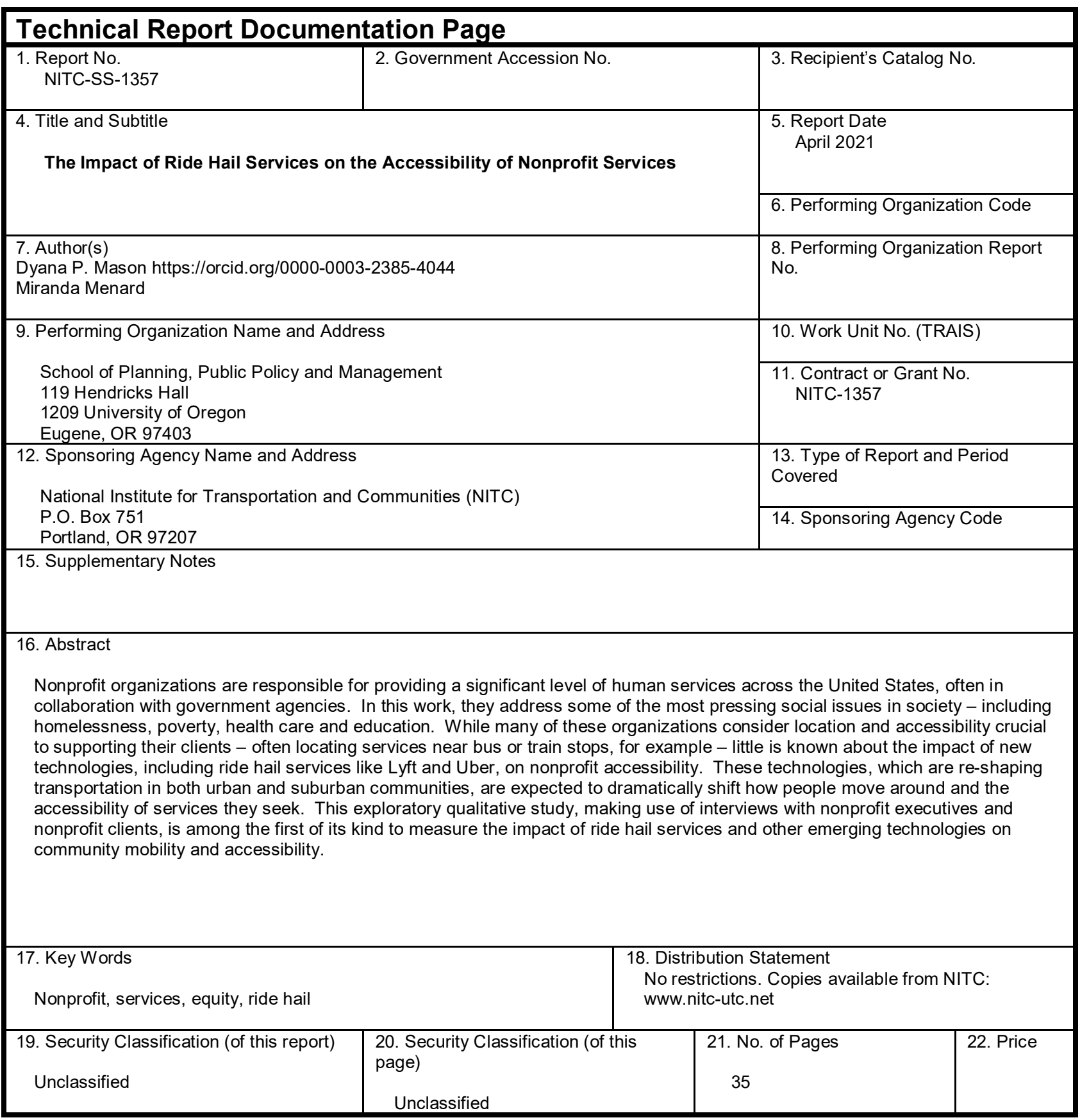




\section{ACKNOWLEDGEMENTS}

This project was funded by the National Institute for Transportation and Communities (NITC; grant number NITC-RR-1357), a U.S. DOT University Transportation Center).

\section{DISCLAIMER}

The contents of this report reflect the views of the authors, who are solely responsible for the facts and the accuracy of the material and information presented herein. This document is disseminated under the sponsorship of the U.S. Department of Transportation University Transportation Centers Program and other in the interest of information exchange. The U.S. Government assumes no liability for the contents or use thereof. The contents do not necessarily reflect the official views of the U.S.

Government. This report does not constitute a standard, specification, or regulation.

\section{RECOMMENDED CITATION}

Mason, Dyana P. and Miranda Menard. The Impact of Ride Hail Services on the Accessibility of Nonprofit Services. NITC-RR-1357. Portland, OR: Transportation Research and Education Center (TREC), 2021. 


\section{TABLE OF CONTENTS}

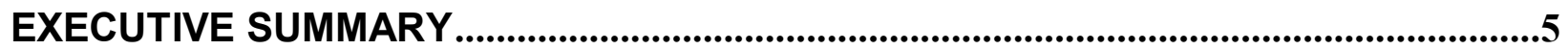

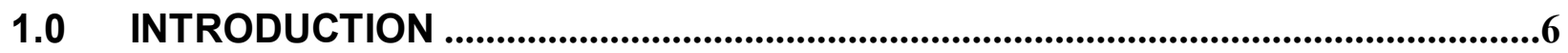

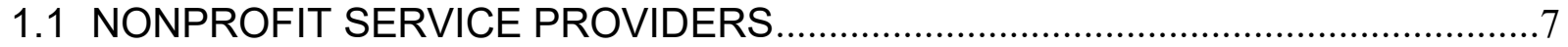

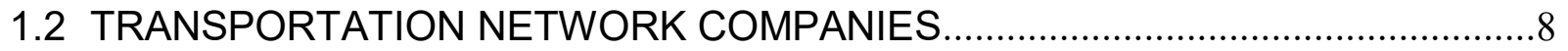

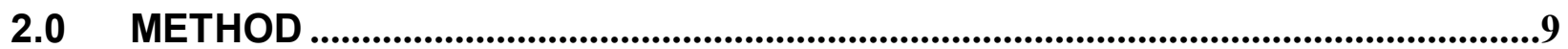

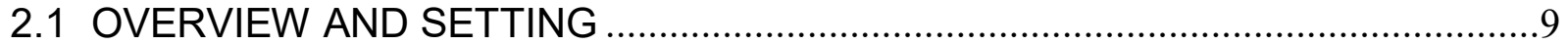

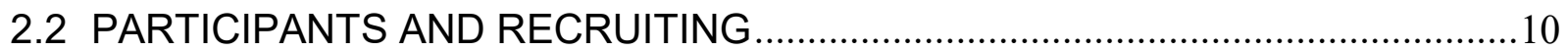

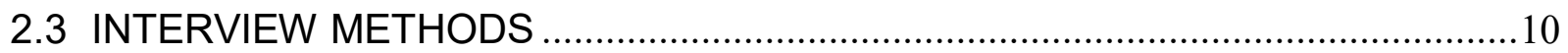

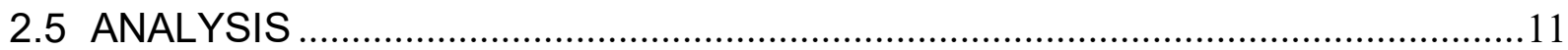

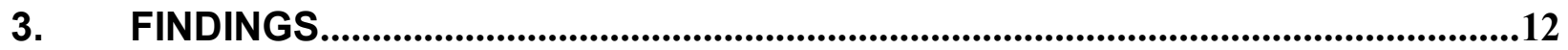

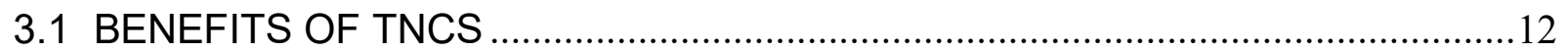

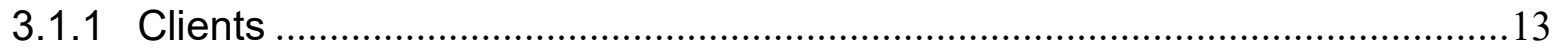

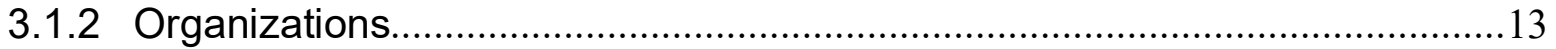

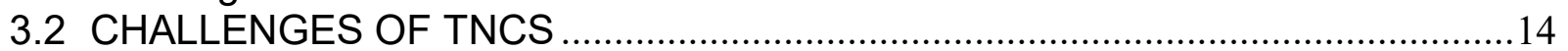

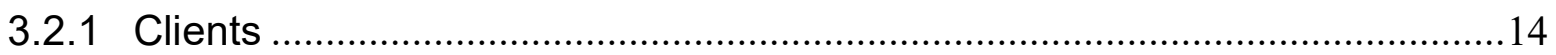

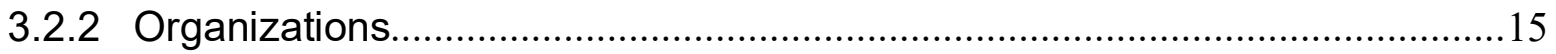

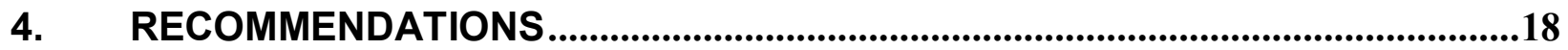

4.1 INCREASING OUTREACH TO UNDERSERVED COMMUNITIES REMAINS A

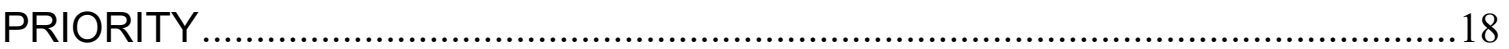

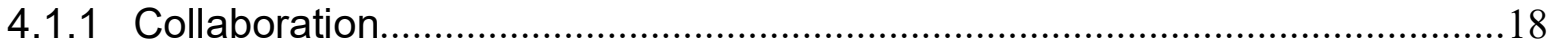

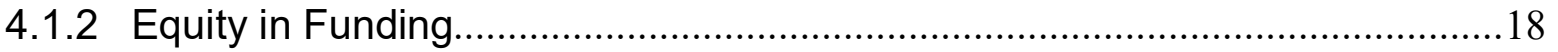

4.1.3 Knowledge of Underserved Communities ...................................................18

4.2 ENCOURAGE NONPROFIT MANAGERS TO INTEGRATE TNCS INTO OFFERINGS

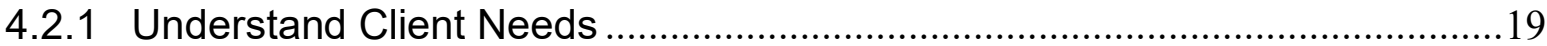

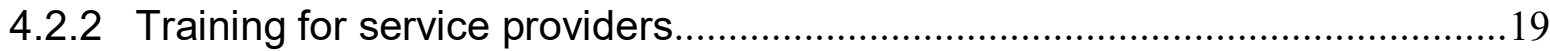

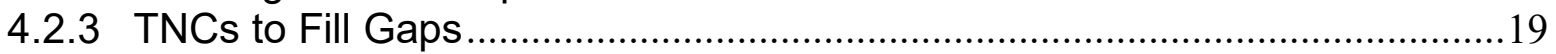

4.3 NONPROFIT USE OF TNCS WILL REQUIRE SUBSIDIES TO BE SUSTAINABLE

4.3.1 Expansion of Grants

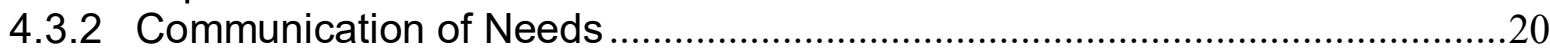

4.4 TNCS AND NONPROFITS CAN DEVELOP AND USE NEW TECHNOLOGIES TO

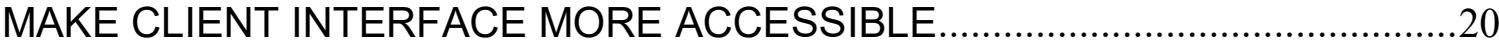

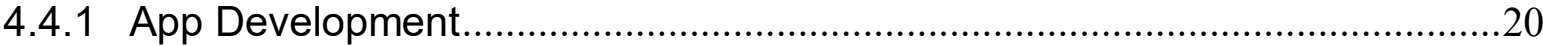

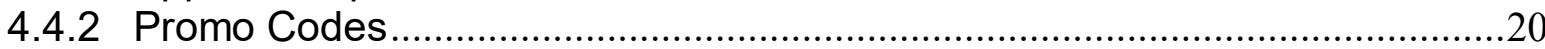

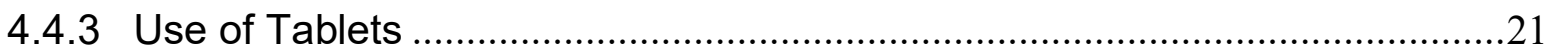

4.5 WIDER USE OF TNC VEHICLES THAT ARE WHEELCHAIR ACCESSIBLE.....21

4.5.1 Increased Use of TNCs for Clients not Using Wheelchairs ............................21

4.5.2 Increase Wheelchair-Accessible Vehicles by TNCs ........................................21

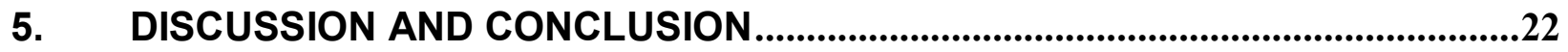

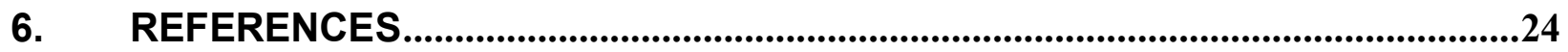




\section{APPENDICES}

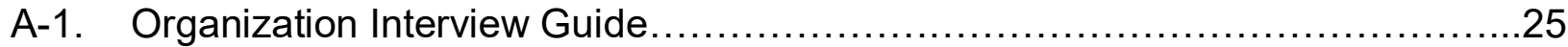

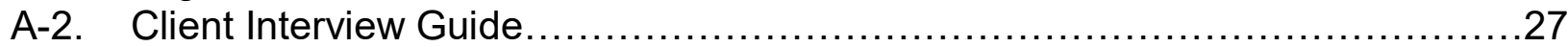

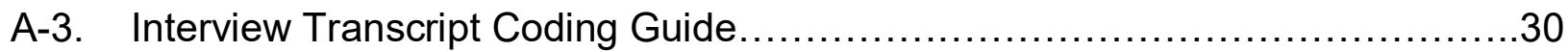




\section{EXECUTIVE SUMMARY}

Nonprofit organizations are responsible for providing human services across the United States, often in partnership with government agencies (Smith and Lipsky, 1993). In this work, they address some of the most pressing social issues - including homelessness, poverty, health care and education (Andrews and Entwistle, 2010). While many of these organizations consider location and accessibility crucial to supporting their clients - often locating services near bus or train stops, for example - little is known about the impact of new technologies, including ride hail services (also called Transportation Network Companies, or TNCs) like Lyft and Uber, on nonprofit accessibility. These technologies, which are reshaping transportation in both urban and suburban communities, are expected to dramatically shift how people move around and the accessibility of services they seek. Do these services help fill gaps in client needs? How are nonprofit organizations considering these services in meeting client needs?

This exploratory and qualitative study is among the first of its kind to measure the impact of TNCs and other emerging technologies on community mobility and the accessibility of human services, helping to build stronger communities. This study includes interviews with nonprofit service providers in Seattle to explore the ways nonprofit managers are thinking about leveraging the benefits offered by TNCs and other transportation services. It also includes interviews with a small number of clients of nonprofit social service providers to better understand their views and use of TNCs.

Research Questions:

1. Are nonprofits located in neighborhoods that are served effectively by TNCs and other mass transit options?

2. What are the opportunities and obstacles facing nonprofit leaders and policymakers in leveraging TNCs for increased mobility and services provided by nonprofits?

3. How do clients of nonprofit services use TNCs along with other transit options to access social services?

Findings suggest that nonprofit organizations are using TNCs to supplement current transportation supports for their clients. However, this use is uneven and largely dependent upon available subsidies, through grants and contracts, to pay for the services. Organizations also reported significant staff capacity needs to support comprehensive use of TNCs for their clients. In addition, clients generally find TNCs convenient and preferable to some other forms of transportation, including buses and access shuttles, but obstacles do remain regarding the use of smart phones, having a credit card, language barriers and a limited number of options for those with disabilities - particularly those in wheelchairs and/or with cognitive disabilities. Finally, while TNCs 
can better serve those coming from or going to "transit deserts," where transit services are relatively limited, there are often not as many TNC drivers in those areas. Nonprofit managers and policymakers should consider both the benefits and challenges when considering expanding use of TNCs for client support.

\subsection{INTRODUCTION}

Nonprofit organizations are key partners with government in the delivery of public services (Grønbjerg, 2001; Salamon, 1995; Smith and Lipsky, 1993). In this work, they address some of the most pressing issues in society - including homelessness, poverty, health care, food insecurity and education (Andrews and Entwistle, 2010). Both public managers and nonprofit practitioners should be concerned about the accessibility of those services to those who use them. Yet, research on accessibility of services, particularly in relation to the transportation options clients need and use, has not been fully explored in the literature. While many nonprofit organizations consider location and accessibility crucial to supporting their clients - often locating services near bus or train stops, for example - less is known about the impact of new technologies, including transportation network companies (TNCs, also called ride hail services) like Lyft and Uber on service accessibility.

TNCs, which are reshaping transportation in both urban and suburban communities, may offer opportunities to fill gaps left behind by government provision and other transportation options. This may be particularly important for communities that are underserved by those other options, which are sometimes called transit deserts (Barajas and Brown, 2021).

Responding to the needs of communities and organizations, this study seeks to answer the following questions. Do TNCs help fill gaps in client mobility needs? How are nonprofit organizations considering these services in meeting client needs? How do clients use TNCs to access social services and what are the obstacles to their use? This qualitative and interdisciplinary study is among the first of its kind to consider the impact of TNCs on community mobility and their roles in providing access to nonprofit services. It leverages interview data from nonprofit executives and clients in Seattle to explore the ways nonprofit managers are using the benefits offered by these services and other transit options while overcoming challenges. This study informs our understanding of access to nonprofit services - especially those often provided for by government grants and contracts - with the hope to inform the development of evidence-based strategies for public and nonprofit managers seeking to reach clients who do not have access to personal vehicles or other transit options. 


\subsection{NONPROFIT SERVICE PROVIDERS}

The provision of social services by government has been a key pillar of the policy agenda of many local, state and federal agencies over the last century as societies moved from solely funding human services through charity towards one of public-sector finance and control (Kendall et al., 2006). Despite this trend towards government provision, the new public management paradigm of the 1980s and 1990s significantly shifted direct service provision back to the nonprofit sector (Lipsky and Smith, 1989; Smith and Lipsky, 1993). As this shift to privatize the provision of human services picked up steam, nonprofit organizations became the provider of choice for many services once provided directly by government (Grønbjerg, 2001). Indeed, the policy agenda of governments or agencies is often in close proximity to their relationships with nonprofit organizations (Allard, 2008). In these cases, the government contracts with nonprofit organizations to provide services (Miltenberger and Sloan, 2017; Salamon, 1995; Smith and Lipsky, 1993), and the nonprofit, in providing the service, is therefore implementing public policy (Fyall, 2016; Mason and Fiocco, 2017). Ultimately, nonprofits are a central force in the provision of the social safety net (Allard, 2009).

Lower-income households are more likely to receive social services from nonprofit organizations, but very little is known about the impact of TNCs on the individual's ability to access services. Nonprofit organizations have always considered accessibility of their services when locating sites for service provision - often seeking to locate their organizations near bus and rail lines or offering low-cost or free parking options. Yet, research to date finds that accessibility to services is often uneven within and across communities. In addition, with very few exceptions, the literature on nonprofit service accessibility does not consider the role of TNCs, even if the study was more recently published.

While the goal of many nonprofit organizations is often focused on those most in need filling gaps in service provision left behind by the underprovision of services by both the market and government (Salamon, 1987) - many communities do not experience adequate accessibility to these services. Many nonprofits are located in suburban communities to be closer to clients, or lower operating expenses, but these locations often have fewer mass transit options (Kneebone and Berube, 2013; Roth and Allard, $2016)$. Allard $(2008,2009)$ found that only $63 \%$ of nonprofit service providers welcomed the majority of their clients from within three miles of their organization. Marwell and Gullickson (2013) found unequal distribution of services to those communities most in need. While public funding was associated with more vulnerable and disadvantaged neighborhoods, those organizations that were tasked with serving multiple communities tended to be located in more affluent neighborhoods, and service to the neediest neighborhoods left key gaps in childcare and family services. Freeman Anderson (2017) also found disparities between neighborhoods with large proportions of ethnic minorities and access to health-related services, including food assistance, fitness organizations, civic associations, and social service agencies. In his study of U.K. charities, Clifford (2018) found that communities with less resources had fewer charitable organizations, and those charities were more likely to see charity turnover 
and even dissolution. Bolger (2020), too, in his study of faith-based social service organizations, found that those organizations directed resources unequally across communities, perpetuating racial disparities and problems with access to services. Roth and Allard (2016) found a "considerable mismatch" between Latinx organizations and predominately Latinx immigrant communities. While Latinx immigrants were more likely to find Latinx-serving organizations in their communities, there were only a small number of them and they tended to provide more limited service options. This emerging literature confirms Allard's assertion when he stated, "Taken together, these findings indicate that initiatives to strengthen faith-based and community-based nonprofit organizations are critical steps in achieving a sound public safety net and increasing the availability of assistance to poor populations" (Allard, 2008, p. 91).

\subsection{TRANSPORTATION NETWORK COMPANIES}

While not much yet is known about the use of TNCs by nonprofit service providers, there is a growing body of research about who uses TNCs and why. Research is in its early stages regarding how individuals can use TNCs to overcome traditional barriers to accessing needed services, or whether they may be inadequate and even exacerbate inequalities (Dillahunt et al., 2017). Hall et al. (2018) found that while TNCs can act as complements to other transportation options, their use is rather uneven depending on neighborhood socio-economic status, the needs of individual riders and access to other transportation options (Halpern et al., 2020; Lefler and Castillo, 2019). Additionally, while Feigon and Murphy (2018) found that as TNC use increases car ownership decreases, Conway et al. (2018) found that wealthier and more urban households are more likely to use TNCs compared to lower-income households.

Others have explored how TNCs have started to shape service provision - although not always by nonprofits. Halpern et al. (2020) found that as taxi services have declined due to the rise of TNCs, some cities are starting to test programs using TNCs to provide subsidized rides to seniors, those with disabilities and, in some cases, low-income individuals. In addition, Powers et al. (2016) explored the use of TNCs in medical care, with particular attention to the impact on patient compliance in attending necessary appointments, and demonstrate that TNCs can provide an important addition to existing transit services. Similarly, attention has been paid to understanding the opportunities and barriers TNCs offer to seniors, finding that while these services do increase the overall number of trips (increasing mobility) barriers remain, including effective use of smart phones (Mitra, Bae and Ritchie, 2019). Freund et al. (2020) found that safe and accessible transportation options are important for older adults' health, safety, mobility, and independence. In their study of TNC use and subsidies, Halpern et al. (2020) found that TNCs are one option to help transport clients, particularly in low-density areas or at night. In addition, some cities have begun to pilot TNCs as a mass transit option, subsidized by local government, both to replace traditional transportation options (Cecco, 2019) or to provide transportation for an individual's "first and last mile" (to and from other transit hubs) (Murphy, Karner and Accuardi, 2019). Taken together, the growing literature indicates the opportunity for nonprofits to support increased mobility for their clients through TNCs. 


\subsection{METHOD}

\subsection{OVERVIEW AND SETTING}

This study utilized semi-structured interviews with nonprofit leaders and clients of community service nonprofit organizations in the Seattle metropolitan region during the summer and fall of 2020. Metropolitan Seattle was selected for the study because the city is a leader in offering a wide array of transportation options to individuals who need or choose to use them. Seattle is also a leader in the adoption of new transportation technologies, including Uber and Lyft. Metro Seattle is defined by the U.S. Census Bureau as made up of the cities of Seattle, Tacoma and Bellevue, along with King, Snohomish and Pierce counties. It is home to nearly 4 million people. According to the 2010 Census, the largest population groups are those who are white at $70 \%, 11.4 \%$ Asian, 9\% Latino or Hispanic, and 5.6\% African-American. According to the City of Seattle, in $201418 \%$ of city residents were foreign born, with Washington State being the $8^{\text {th }}$ largest refugee-receiving state in the country.

Seattle enjoys a robust public transportation system with multiple modes of transportation available to a significant portion of the population - dominated by Metro Seattle, the public transit agency of King County. The city, and King County, utilize buses, commuter trains, the Central Link light rail, and the Seattle Streetcar lines. Many communities are also connected by public ferry service. Those outside of King County can take advantage of Sound Transit, which covers areas of Snohomish and Pierce counties, and some areas in common with King County and Metro. For those individuals who are not able to take advantage of the primary options of Metro, King County provides Access buses and shuttle vans that can be used by making a reservation, usually at least several days in advance. One must also be eligible for paratransit. Additionally, some community organizations offer shuttles or volunteerdriver services to individuals who need a ride; however, the reach of these programs is often limited. Volunteer drivers are those who volunteer for an organization to provide rides to that organization's clients, often using their own cars (for which they are reimbursed for mileage driven). Metro Seattle also contracts with community nonprofit organizations to provide Medicare-funded transportation for individuals, particularly those who need to get to medical appointments.

Finally, a number of the nonprofits in the sample had also been awarded an Uber Community Impact Initiative Grant (https://www.uber.com/us/en/community/givingback/). These grants provided them with credits to use in offering their clients Uber rides. In these cases, it was most frequently the nonprofit organization that assisted clients in using the TNC, including setting up the ride for clients and communicating the information on the driver, vehicle, time and location for pickup to the client. More on this arrangement will be discussed below. 


\subsection{PARTICIPANTS AND RECRUITING}

Interview subjects were identified using a snowball technique, developing referral chains, with nonprofit leaders being asked to provide recommendations for additional leaders to contact. It is important to note that the outreach for interviews was conducted during the COVID-19 pandemic, requiring that all interviews be handled remotely. While this offered an opportunity to explore the impact of the pandemic on vulnerable communities, it also added additional challenges to identify users who either did not have access to a phone or computer, or for clients and users who do not share contact information with the nonprofit organizations that provide them services (such as drop-in centers or other anonymous services). It also provided a challenge to communicate with organization leaders who were not working in their offices, and for those with whom English was not their native language. These challenges made recruitment into the study difficult, leading to a smaller than optimal number of interviews.

Beginning with large regional nonprofit network organizations and a significant funder, the authors sought recommendations for other organizations and leaders, and were often provided email introductions. Organizations that agreed to participate were also asked to help recruit a small number of their clients (Singleton, Jr. and Straits, 2005). While snowball sampling leads to challenges with the generalizability of findings, it offers benefits when research is "emergent, political and interactional" (Noy, 2008, p. 321 ), and assumes that individuals often know each other. In this study, the sampling relied upon a network of nonprofit organizations that work alongside each other in providing services to their clients. Organization leaders were contacted via email and phone, and interviews were conducted and recorded online. Ten interviews with eight nonprofit organizations were conducted, along with 10 clients of three of the nonprofits. Leaders with organizations took approximately 45 minutes to an hour, and interviews with clients took approximately 15 to 45 minutes. Those who participated in the interviews included leaders and clients from organizations located in urban Seattle districts, as well as those in outlying suburban areas. Groups included those serving seniors, those with developmental and cognitive disabilities, those providing food supports, and other organizations who provide a broad range of services to their clients. Interviews with clients included those with disabilities, low-income individuals, seniors and one recent immigrant to the United States. Clients interviewed received a $\$ 25$ gift card for their time.

\subsection{INTERVIEW METHODS}

Leaders were asked questions about their organization's operations and programs, whether and how they offer transportation services to their clients, the challenges and benefits of different modes of transportation (such as buses, volunteer drivers, TNCs, or organization vans and shuttles). Interviews with clients and users consisted of questions about their own uses of different transportation options, and the challenges and benefits of each. Interviews were completed by phone or online using Zoom. When possible, conversations were recorded. Some phone conversations were unable to be recorded due to technology limitations. In these cases, detailed notes were kept and a 
short interview summary was written following the interview. See Appendix A1 and A2 for interview guides for both leaders and clients.

\section{5 [AB1]ANALYSIS}

Interview recordings were transcribed using an online service, reviewed for accuracy, and then manually coded by the authors using an inductive process based on themes that had emerged in the interviews (Thomas, 2006). After the interviews were complete, the research team discussed their overall impressions of the interviews, and a list of items to be coded was created. Researchers then reviewed each interview, manually coding the items that were included in each of the themes below. These themes included:

1. Cost - Referring to the cost of various transportation options, including TNCs, taxis, buses or volunteer services. This was coded for both organizations and individuals.

2. Logistics - This code referred to the use, booking, reservation and referral process for any type of transportation service, with subcodes for either the individual or organization.

3. Accessibility - Related to accessibility, with subcodes based on disability, lowincome individual, or use of TNC or other phone applications.

4. COVID-19 Challenges, Benefits and Opportunities - This study provided an opportunity to also evaluate the impact of COVID-19 on accessibility and use of TNCs and other transportation options.

5. TNC Challenges, Benefits and Opportunities - These code(s) referred to discussions around the use of TNCs for transportation, and their associated challenges, benefits and opportunities.

6. Bus Challenges, Benefits and Opportunities. Same as above, except based on experiences with the use of buses.

7. Community Shuttle Challenges, Benefits and Opportunities. Same as above, but based on some use of private shuttle services used by nonprofits.

8. Access Shuttle Challenges, Benefits and Opportunities. Same as above, but based on client use of city and county-run access shuttles.

9. Volunteer Driver Challenges, Benefits and Opportunities. Same as above, but refers to the use and experiences of volunteer driver services run by nonprofit organizations.

10. Independence - Refers to different modes of transportation either facilitating or hampering individual independence.

11. Social Benefits - Refers to stated social benefits that mobility provides through various transportation options.

More than one code could be applied to a section or quote of the interview. For example, if a participant was discussing accessibility challenges with bus services for those with disabilities, the item would be coded as "Bus Challenge" and "Accessibility Disability." The coding guide can be found in Appendix A3. 


\section{FINDINGS}

Both clients and nonprofit executives agreed that the patchwork of transportation options available to those in need of transit support to access services was often not adequate to serve client needs. The general consensus by all interviews also suggested that while TNCs like Uber and Lyft can be useful additions to transportation networks and services, and have some important benefits to certain groups of individuals, they also pose challenges to clients who need regular assistance getting to appointments, activities and other services. The section below describes both the benefits and challenges of Uber and Lyft. In addition, many respondents shared recommendations regarding the use of TNCs to help better support clients.

To describe how organizations may use TNCs to support client mobility, one leader described how they use them. She stated:

"It was largely to get folks to events, like one stop events where they were in a noncentral location, or where people were getting a lot of supplies. So, we do one stops for people to get access to housing and other resources, and then they would just get clothing and all this stuff and they weren't going back in a bus. So, we started using Lyft and Uber..... Initially it was super low tech. Like we were all using our own Uber accounts at the end of an event, sending people to and from events. Now we have an account and we can sign people up and it, it works most of the time. [However] they're still not really designed for those purposes. So you end up with the client or the end user, there's just confusion."

In addition, of particular attention in this study is the impact of TNC use on community mobility in traditionally underserved communities, including those with low incomes, people of color and immigrant communities, those with disabilities, those for whom English is not their first language and those living in transit deserts. Human services providers not only provide, for example, food, but many organizations also provide case support for their clients, which requires helping the client meet more of their needs (such as going shopping).

\subsection{BENEFITS OF TNCS}

Both organizations and clients do use TNCs. Clients, to get to appointments and activities and nonprofits, to help their clients access services by their organization and other organizations. Overall, TNCs were seen as having better service than traditional taxis, and were perceived as more convenient and easier to use than all other transportation options except for the popular volunteer driver programs offered by a small number of organizations. 


\subsubsection{Clients}

Individuals who either don't drive, or don't have access to a car, do use TNCs to complement their transportation options to obtain the services they need. In many ways, TNCs offer options to traditionally marginalized communities that other modes of transportation, such as bus, taxi or train, do not. For one, TNC drivers are generally perceived to be more friendly than traditional taxi services. The county's access shuttles were ranked unsatisfactory by most interview subjects, as the shuttles require reservations several days in advance, were often cancelled, and also often required clients to wait for several hours after an appointment or errand to be picked back up and taken home. Many respondents discussed the quality of the service received from TNCs, and how they are able to come right to the location where someone is at (home or where they got an appointment). One respondent, who has a disability, discussed in detail how other options for them were not ideal. They stated:

"I was making what probably would be considered a low salary, the benefit of Uber was so, so important because I wouldn't have to deal with the physical exhaustion of having stood up for the first hour of my day. Like, you know, you're barely awake and it's just not a good time. So, um, even though it was costing me and it's like an obscene amount, like $\$ 400$ a month on an average month, I was more than happy to do that because of the benefits that it gave me physically to not have to use the train."

TNCs were also perceived favorably because they came quickly and directly to their location. This made making appointments easier than perhaps waiting for other options, like the Access buses paid for by the county. They were also appreciated for the safety guidelines that have been recently implemented, including being informed of the model of the car and the driver's name and picture, which makes it easier to match the rider with their specific driver. These were noted to be particularly important for those who may have cognitive disabilities.

Several clients mentioned that their ride(s) with a TNC was arranged by the nonprofit they were working with. For example, a staff person at the organization would identify the need for a ride with the client, then arrange for the ride directly with the TNC, billing their organization account or TNC credits for the ride. One rider stated, "I did not ever call Uber myself. They [nonprofit] called them for me, gave them the appointment information about picking me up and take me where I was to go."

TNCs were also mentioned as providing a level of independence that other options failed to do. Specifically, one client mentioned that she was worried about over-asking friends to take her to appointments. Others mentioned that they like to be able to get to where they want to go when they want to go.

\subsubsection{Organizations}

While some respondents organized rides for their clients through volunteer driver programs, others also provided bus passes and Metro cards for their clients to use. 
Yet, TNCs can, for lack of a better term, "fill the gaps" when other supports aren't adequate. For one, it can provide "first and last mile" access to clients who need assistance getting from their home or other location to a bus or train stop, where they can complete their journey.

Second, one organization that used TNCs as a backup when their volunteer drivers weren't available found that they were able to serve a much higher proportion of client needs once they started using TNCs for rides they couldn't find a volunteer for. Previously, the organization would have to deny transportation to that client when a volunteer driver could not be assigned, sometimes with short notice. This was especially the case in more outlying communities of their service area. One leader stated, "The east part of our county is really underserved in the transportation system. And so we've used probably Uber more there." However, it is important to recognize that most nonprofit organizations used TNCs due to grants that were offered to them directly from TNCs, usually in the form of ride credits.

Third, organizations can and do use TNCs to help get low-income clients around. One leader stated:

"It was affordable when we were paying for rides for people when we had that support from [a TNC-funded grant]. We do some homelessness and housing instability work. And so, it was actually a fair number of people using it were people who already were strapped for money. And so, it was just helping them get to work and helping them go grocery shopping and not have to spend their own money out of pocket. And then it was also helping them engage with [our] activities. Like, if we have support groups or community activities or doing some sort of public advocacy or something, it would help people participate."

TNCs were also listed as good options to help transport families, to help those with vision impairments, and for those who were travelling for evening appointments or activities.

\subsection{CHALLENGES OF TNCS}

Organizations and clients both recognized some challenges in the use of TNCs. Unlike other forms of transportation (with the exception of taxis), ride-hail services can be prohibitively expensive for low-income individuals and families. In addition, TNC use by organizations can require a high level of organization capacity to organize on behalf of their clients. Finally, some challenges remain for TNC use by those with physical or cognitive disabilities.

\subsubsection{Clients}

By far, the most significant challenge recognized was cost. Many clients expressed that without the nonprofit paying for the TNC, they would be unlikely to use it on their own. 
This was particularly acute for those with lower incomes, especially senior citizens. As one respondent simply said, "The main problem I have living on Social Security at the moment is I don't have the type of funds to go on Uber on a regular basis." Other respondents talked about some confusion using the app, including accidentally getting charged for a ride when it was the organization that should have been paying for it.

However, for those with disabilities, they had much to say about some of the challenges with using TNCs to meet their needs. For one, most TNC vehicles are not outfitted to be able to accommodate those who use a wheelchair. Some markets do have wheelchair-accessible vehicles, but if they do, to date they are few and far between. There is also the added challenge of needing some support getting into and out of the vehicle. One respondent stated that "people that are in wheelchairs, they can't get out [of the car]." In addition, a couple of respondents discussed the fact that for those with cognitive disabilities, using TNCs might be difficult or dangerous due to challenges using the app, being able to identify their scheduled driver or giving instructions.

\subsubsection{Organizations}

Although TNCs provided options for nonprofits, there were several challenges associated with using them regularly. Traditionally under-served communities, including those with disabilities, immigrants, and those in outlying areas were particularly hard to support due to cost, language barriers and physical needs. For example, in speaking about immigrant communities, one leader stated, "Language is also a barrier. You know, [clients] are unable to communicate what they're needing or understand what others are trying to communicate to them." Some organizations were making strides to intentionally outreach to traditionally under-served communities, but other organizations had placed similar efforts on hold due to the pandemic.

Some leaders also spoke of their efforts to improve their outreach to these communities. One organization leader discussed connecting to underserved communities through other community-based organizations. They stated that they are developing a "companion program with the focus of serving underserved communities, contacting and discussing with the community-based organizations who are already providing services to these folks, identifying volunteers and the clients from the community, from their own network and provide a service, which is not restricted to just medical needs."

Another stated, "Some of the drivers are very accommodating and some are not. And so that's been a challenge for us in particular, or we're working there picking up an immigrant client who thinks they're in the right place. But, maybe they try to call or text the client, but you know, they're confused and just really depends on the driver. That said, many of the drivers themselves are immigrants. So, um, you know, maybe it's just the language or communication difficulty, but it's not set up in the same way as our government funded service." 
As mentioned above, nonprofit organizations primarily used grant funds to cover the expense of the rides for their clients. In addition, current grant funds and available county contracts for transportation often only cover transportation costs for medical appointments - leaving significant unfilled gaps to provide transportation for other services.

Without a subsidy, either by the TNC providers or government grants, nonprofits would use TNCs much less frequently. One leader stated, "The obstacle is really the financial piece and the budgeting and all. It's not a cheap service, really."

Outside of the cost of the rides, however, the other main cost to organizations is the capacity necessary to support their clients' TNC rides when the organization was the one organizing and paying for them. This was stated clearly by one leader who said, "Uber rides are much more time intensive for staff to do as they [the staff] serve essentially as a smart phone for [a] rider who does not have a smart phone." That is, it is the organization's staff that identifies the client needs and books the ride for the client through the TNC. They also must stay in contact with the client, and sometimes the driver, if there is confusion about where the client is located or what the TNC vehicle looks like.

Like clients, nonprofit organizations discussed the accidental charges clients experienced trying to use the app in a way that didn't bill the organization. One stated, "This was another problem in that we had some clients who got Uber accounts and, um, spend a ton of money unknowingly. Because, it's like, you just press the button and a ride shows up and it actually became problematic." These organizations then had to complete additional paperwork to help reimburse their clients for rides taken. Other clients would use organizational credits, but then their clients would end up taking rides that were more expensive than provided for by those credits. Additionally, unbanked clients who do not have a bank account are unable to use TNC apps.

Accessibility for their clients was also highlighted by nonprofit leaders. One leader stated,

"For example, we had one of our participants who regularly attended our meetings. She was very low vision. She had extremely different experiences using Uber versus Lyft. She preferred Lyft. She, she thought the drivers were more receptive and accessible, but it ultimately came down to a per driver basis. I think that's probably another factor beyond the affordability is that, it would be interesting to think about the kind of clients that nonprofits are serving and if some of those on demand ride hailing services are able to accommodate needs as much as a specifically trained transportation provider service would."

Lastly, nonprofits continue to experience challenges using TNCs in reaching some traditionally underserved communities, particularly those for whom English is not their first language, and those who live outside of major transportation networks. 
One leader put the challenges of using TNCs quite succinctly:

"I think the biggest barrier is finances. And then the second barrier is accessibility. And that includes both, you know, the physical, like wheelchair-based accessibility as well as sort of the disability sort of bias or understanding side of accessibility." 


\section{RECOMMENDATIONS}

\subsection{INCREASING OUTREACH TO UNDERSERVED COMMUNITIES REMAINS A PRIORITY}

Several organization leaders discussed remaining gaps in their ability to effectively reach out to and serve underrepresented communities, including immigrant communities, lower-income individuals, those with cognitive or physical disabilities, those in outlying areas and those who do not speak English as their first language. While individuals and families from underserved communities may use other forms of transportation, including buses, many may benefit from access to TNCs and other services that nonprofits organize, including volunteer driver programs and community shuttles. This is particularly important for those individuals who live in areas outside the core mass transportation service areas.

We recommend that nonprofits work together to identify and serve clients from communities that have traditionally been underserved by their organizations.

\subsubsection{Collaboration}

Nonprofit organizations should collaborate with other organizations to support outreach to different communities. Larger organizations may be able to better communicate with hard-to-reach populations by partnering with smaller, community-based groups. This was a strategy being developed by one of the organizations in our sample. Smaller organizations with no capacity to support client transportation can partner with larger organizations with more resources. Local or state agencies can also help to coordinate these efforts. Working together, can better identify those who need rides and connect clients of smaller groups to the services offered by larger ones.

\subsubsection{Equity in Funding}

Policymakers should consider equity and access in providing grants to organizations to support transportation services. Specifically, government agencies may be able to provide grants to underwrite rides for underserved populations, particularly those who live in more outlying areas, or targeting specific communities such as recent immigrants. Grants could also be provided to allow for community outreach and education to hardto-reach communities about their options in contacting key nonprofit providers.

\subsubsection{Knowledge of Underserved Communities}

Policymakers and planners should continue to develop knowledge of underserved communities, and create and implement plans to better serve them. This is particularly important for transit deserts and outlying suburban and rural areas that rely upon nonprofit services available in an urban core. 


\subsection{ENCOURAGE NONPROFIT MANAGERS TO INTEGRATE TNCS INTO OFFERINGS}

This study explored transportation needs with organizations that currently use TNCs. A few other organization leaders declined to be interviewed for this study by saying "we don't use TNCs, I'm not sure why you are asking us." These organizations either did not recognize how TNCs might be helpful for their operations or clients or had dismissed the option. More research can be conducted to explore organization barriers to TNC use.

\subsubsection{Understand Client Needs}

Nonprofit organizations should work with policymakers and planners to inform decision makers of client needs, and the benefits and challenges of using TNCs to meet those needs.

\subsubsection{Training for service providers}

Training for service providers - whether public or nonprofit - can be offered and implemented by funders in the philanthropic and public sectors. These trainings can include best practices in using TNCs, how to access funding to support TNC use, and other supports nonprofits can use in client transportation, including subsidized bus pass programs, access shuttle accessibility and volunteer driver programs.

\subsubsection{TNCs to Fill Gaps}

Nonprofit organizations would be well served to consider using TNCs to supplement any other transportation options they may currently provide their clients, including bus passes, arranging taxi service, or a community shuttle. TNCs can be particularly helpful in arranging transportation for the first and last mile of a client trip.

\subsection{NONPROFIT USE OF TNCS WILL REQUIRE SUBSIDIES TO BE SUSTAINABLE}

TNCs offer opportunities to meet the needs of clients not well served by other modes of transportation (bus, taxi, private vehicles or train service), yet they will not be able to fill gaps in current transportation systems without government subsidies and support (Jiao and Wang, 2020). This supports other findings on transit deserts (Barajas and Brown, 2021), as well as clients who live in areas that are not as well served by nonprofit organizations (Bolger, 2020; Marwell and Gullickson, 2013; Roth and Allard, 2016).

Most nonprofit organizations do not have the capacity to use TNCs at significant levels in their operations without financial support from either government or private foundations. The reported costs to the organization in terms of paying for trips, as well as the intensive staff support necessary to coordinate rides for clients, make use of 
TNCs unsustainable and growth in using TNCs impractical. While there is an interest in having TNCs fill gaps in current or future transportation planning, policymakers should consider how to finance TNC use by nonprofit organizations.

\subsubsection{Expansion of Grants}

Government agencies should consider expanding grants to nonprofits for use of TNCs, particularly to support rides from underserved areas or specifically among underserved populations. For example, the Job Access and Reverse Commute (JARC) program offers low-income individuals transportation subsidies to ensure continued employment. The program's primary recipients are state and local governments, although nonprofits are eligible to apply as subrecipients. By enhancing nonprofit organizations' eligibility as primary recipients of this federal program, more organizations may be able to access funds helpful to supporting client needs.

\subsubsection{Communication of Needs}

Nonprofit managers should communicate client transportation needs to private foundations in order to encourage increased philanthropy to support TNC costs. In the past, some transit agencies have provided vouchers for taxi use. By supporting TNC use, similar programs can benefit their clients with a service that is perceived by many to be higher quality (Brown and LaValle, 2020).

\subsection{TNCS AND NONPROFITS CAN DEVELOP AND USE NEW TECHNOLOGIES TO MAKE CLIENT INTERFACE MORE ACCESSIBLE}

Several organizations described the intensive staff time necessary to coordinate client rides for their clients using TNCs. There was also confusion about billing and clients were often confused about who was paying and occasionally were accidentally billed themselves. Some nonprofit staff members paid for rides through their own personal accounts, requiring additional paperwork in order to be reimbursed.

\subsubsection{App Development}

TNCs can develop an app for use by nonprofits or other organizations that allows them to communicate with their clients and assist with booking and paying for rides. For example, Lyft Business (www.lyftbusiness.com) provides an easy interface for health services providers to book rides for their clients. Making these types of interfaces more widely available to nonprofit organizations would reduce staffing needs.

\subsubsection{Promo Codes}

TNCs can offer user codes that organizations can provide to their clients, billing more efficiently to a central organizational account. For example, for those with a smart phone and access to the app, they can book their own ride paid for with a promo code, 
which is billed to the organization. Organizations can set parameters on allowable distance and cost. This can circumvent most necessary staff capacity, allowing clients to book their own rides.

\subsubsection{Use of Tablets}

Nonprofits can use tablets or computers at sites to connect clients without rides to TNCs. Once travel and gathering restrictions are lifted due to COVID-19, nonprofits may want to consider installing tablets or iPads in common areas where clients may be able to log in and book a ride with a TNC, paid for by the nonprofit.

\subsection{WIDER USE OF TNC VEHICLES THAT ARE WHEELCHAIR ACCESSIBLE}

Many nonprofit clients, including seniors and those with disabilities, use wheelchairs and other mobility aids. Several organization leaders and clients mentioned that TNCs have limited availability of vehicles that are able to take riders using wheelchairs. This is particularly important for those individuals that live in areas outside the core mass transportation service areas. Others described the more limited training TNC drivers might receive in supporting those with cognitive limitations. One leader discussed the inability for TNC drivers to assist riders in leaving the location and getting into the car.

\subsubsection{Increased Use of TNCs for Clients not Using Wheelchairs}

TNCs may help provide more accessible services to those who do not need a wheelchair, allowing those who need wheelchairs to use a higher proportion of paratransit services. Those with mobility devices that are difficult to get in and out of cars (even when a car is able to fit them in a trunk or designated area) may not be able to currently use TNCs in many markets. This challenge also applies to those with more serious cognitive disabilities. These individuals should get top priority in using subsidized public transportation, including Access shuttles.

\subsubsection{Increase Wheelchair-Accessible Vehicles by TNCs}

Policymakers may require TNCs to provide enough wheelchair-accessible vehicles to be adequate for the population. Some jurisdictions have already begun this process, including California which recently passed the TNC Access for All Act (https://www.cpuc.ca.gov/tncaccess/). This law requires the California Public Utilities Commission to regulate TNCs for the number of wheelchair accessible vehicles (WAV) in any given area. Additionally, the U.S. Department of Justice settled a lawsuit in 2020, holding Lyft accountable denying rides to those in wheelchairs (Heasley, 2020). 


\section{DISCUSSION AND CONCLUSION}

Nonprofits are using TNCs, some of them quite effectively, to supplement existing transportation needs for their clients. TNCs are most helpful in supporting clients who are not able to use other forms of transportation, such as buses, trains or personal vehicles. They can also help transport clients to and from places that are not otherwise accessible by traditional mass transit options. It is also helpful for those who have some types of disabilities - the ease and convenience of riding in a car that comes quickly to your exact location should not be underestimated. Clients, too, are using TNCs when they are desperate for transportation options that meet their needs, although they tend to use them sparingly, most often because of the price.

However, TNCs should not be considered a replacement for other transportation options unless there are significant subsidies in place for both nonprofit organizations as well as clients to use them. Nonprofit organizations may be interested in using TNCs more widely to help their clients get to events, activities and services if the cost was supported through grants or government contracts. Otherwise, expanding TNCs use will be difficult. TNCs would also be well-served to think about the accessibility of their services in order to effectively serve those who have cognitive or physical disabilities. Nonprofit organizations should also be careful about using TNCs as part of the services they provide to their clients. Organization-assisted TNC rides may significantly tax the capacity of staff as they organize and support the ride from start to end. Those organizations that had both volunteer drivers and used TNCs ended up spending more time supporting TNC use than it took to use their volunteers.

There are a few limitations to this study, however, that should be noted. First, this study was conducted entirely remotely due to the COVID-19 pandemic, which significantly impacted the ability to identify and communicate with nonprofit organizations and their clients. This limited the number of individuals available to be interviewed. Future research could interview and/or survey nonprofit clients in person at service locations, including food banks or employment offices, particularly to get the perspective of those clients who don't register formally with the nonprofit. Second, this study used a snowball method to identify organizations that do already provide transportation services for their clients. That limits the generalizability to the larger group of nonprofit service providers. By broadening the sample to all nonprofit human service organizations, and their clients, it would be possible to gain a more comprehensive understanding of the practices of nonprofits, their clients, and remaining gaps in services. Alternatively, the modest use of TNCs by those groups who do support their clients with their transportation needs - including TNCs, volunteer ride programs or complementary bus passes - suggests that TNCs may not be widely used by other human service providers.

Despite these limitations, this study is among the first to consider the impact of nonprofit services on community mobility and the use of TNCs to help to support that mobility. While scholars have begun to explore the use of TNCs by different populations, and while policymakers and planners are considering how to make the best use of new 
transportation technologies, no study that we have found yet explores how integrating these programs may impact the ability of vulnerable populations accessing services offered by nonprofit organizations in partnership with government. Both nonprofit and public practitioners should consider these lessons when planning for the accessibility of services as urban and suburban areas transform in the coming decades. 


\section{REFERENCES}

Allard, S. W. (2008). Accessibility and Stability of Nonprofit Service Providers: FaithBased and Community-Based Organizations in Urban and Rural America. Innovations in Effective Compassion. Faith-Based and Community Initiatives Conference on Research, Outcomes, and Evaluation, Washington, D.C.

Allard, S. W. (2009). Out of Reach: Place, Poverty, and the New American Welfare State. Yale University Press.

Andrews, R., \& Entwistle, T. (2010). Does Cross-Sectoral Partnership Deliver? An Empirical Exploration of Public Service Effectiveness, Efficiency, and Equity. Journal of Public Administration Research and Theory, 20(3), 679-701.

Barajas, J. M., \& Brown, A. (2021). Not minding the gap: Does ride-hailing serve transit deserts? Journal of Transport Geography, 90, 102918.

Bolger, D. (2020). The Racial Politics of Place in Faith-Based Social Service Provision. Social Problems.

Brown, A., \& LaValle, W. (2020). Hailing a change: Comparing taxi and ridehail service quality in Los Angeles. Transportation. https://doi.org/10.1007/s11116-020-10086-z

Cecco, L. (2019, July 16). The Innisfil experiment: The town that replaced public transit with Uber. The Guardian. http://www.theguardian.com/cities/2019/jul/16/the-innisfilexperiment-the-town-that-replaced-public-transit-with-uber

Clifford, D. (2018). Neighborhood Context and Enduring Differences in the Density of Charitable Organizations: Reinforcing Dynamics of Foundation and Dissolution. American Journal of Sociology, 123(6), 1535-1600.

Conway, M. W., Salon, D., \& King, D. A. (2018). Trends in Taxi Use and the Advent of Ridehailing, 1995-2017: Evidence from the US National Household Travel Survey. Urban Science, 2(3), 79.

Dillahunt, T. R., Kameswaran, V., Li, L., \& Rosenblat, T. (2017). Uncovering the Values and Constraints of Real-time Ridesharing for Low-resource Populations. Proceedings of the $2017 \mathrm{CHI}$ Conference on Human Factors in Computing Systems, 2757-2769.

Feigon, S., \& Murphy, C. (2018). Broadening Understanding of the Interplay Among Public Transit, Shared Mobility, and Personal Automobiles. TCRP Research Report, 195. https://trid.trb.org/view/1523167

Freeman Anderson, K. (2017). Racial Residential Segregation and the Distribution of Health-Related Organizations in Urban Neighborhoods. Social Problems, 64(2), 256276. 
Freund, K., Bayne, A., Beck, L., Siegfried, A., Warren, J., Nadel, T., \& Natarajan, A. (2020). Characteristics of ride share services for older adults in the United States. Journal of Safety Research, 72, 9-19.

Fyall, R. (2016). The Power of Nonprofits: Mechanisms for Nonprofit Policy Influence. Public Administration Review, 76(6), 938-948.

Grønbjerg, K. A. (2001). The U.S. Nonprofit Human Service Sector: A Creeping Revolution. Nonprofit and Voluntary Sector Quarterly, 30(2), 276-297.

Hall, J. D., Palsson, C., \& Price, J. (2018). Is Uber a substitute or complement for public transit? Journal of Urban Economics, 108, 36-50.

Halpern, J., Deakin, E., \& Parker, M. (2020). Examining the Potential for Uber and Lyft to be Included in Subsidized Mobility Programs Targeted to Seniors, Low Income Adults, and People with Disabilities (UC-ITS-2019-14). Institute of Transportation Studies.

Heasley, S. (2020, June 24). Lyft Settles Disability Discrimination Claims With Justice Department. Disability Scoop. https://www.disabilityscoop.com/2020/06/24/lyft-settlesdisability-discrimination-claims-with-justice-department/28523/

Jiao, J., \& Wang, F. (2020). Shared mobility and transit-dependent population: A new equity opportunity or issue? International Journal of Sustainable Transportation, 0(0), 112.

Kendall, J., Knapp, M., \& Forder, J. (2006). Social Care and the Nonprofit Sector in the Western Developed World. In W. W. Powell \& R. Steinberg (Eds.), The Nonprofit Sector: A Research Handbook (2nd ed., pp. 415-431). Yale University Press.

Kneebone, E., \& Berube, A. (2013). Confronting Suburban Poverty in America. Brookings Institution Press.

Lefler, V., \& Castillo, F. (2019). Designing our future transportation workforce for supporting seniors and individuals with disabilities. In T. Reeb (Ed.), Empowering the New Mobility Workforce (pp. 269-288). Elsevier.

Lipsky, M., \& Smith, S. R. (1989). Nonprofit Organizations, Government, and the Welfare State. Political Science Quarterly, 104(4), 625-648. JSTOR.

Marwell, N. P., \& Gullickson, A. (2013). Inequality in the Spatial Allocation of Social Services: Government Contracts to Nonprofit Organizations in New York City. Social Service Review, 87(2), 319-353.

Mason, D. P., \& Fiocco, E. (2017). Crisis on the Border: Specialized Capacity Building in Nonprofit Immigration Organizations. VOLUNTAS: International Journal of Voluntary and Nonprofit Organizations, 28(3), 916-934. 
Miltenberger, L., \& Sloan, M. F. (2017). Collaborative Leadership: The Future of Nonprofit Contracting. The Journal of Nonprofit Education and Leadership; Urbana, $7(2)$.

Mitra, S. K., Bae, Y., \& Ritchie, S. G. (2019). Use of Ride-Hailing Services among Older Adults in the United States. Transportation Research Record, 0361198119835511.

Murphy, C., Karner, K., \& Accuardi, Z. (2019). When Uber Replaces the Bus: Learning from the Pinellas Suncoast Transit Authority's "Direct Connect" Pilot: A First-Last Mile Case Study. Shared-Use Mobility Center. https://learn.sharedusemobilitycenter.org/wpcontent/uploads/SUMC_CaseStudy_Final3_06.21.19-1.pdf

Noy, C. (2008). Sampling Knowledge: The Hermeneutics of Snowball Sampling in Qualitative Research. International Journal of Social Research Methodology, 11(4), 327-344.

Powers, B. W., Rinefort, S., \& Jain, S. H. (2016). Nonemergency Medical Transportation: Delivering Care in the Era of Lyft and Uber. JAMA, 316(9), 921-922.

Roth, B. J., \& Allard, S. W. (2016). The Response of the Nonprofit Safety Net to Rising Suburban Poverty. In K. B. Anacker (Ed.), The New American Suburb: Poverty, Race and the Economic Crisis (pp. 247-284). Routledge.

Salamon, L. M. (1987). Of Market Failure, Voluntary Failure, and Third-Party Government: Toward a Theory of Government-Nonprofit Relations in the Modern Welfare State. Nonprofit and Voluntary Sector Quarterly, 16(1-2), 29-49.

Salamon, L. M. (1995). Partners in public service: Government-nonprofit relations in the modern welfare state. Johns Hopkins University Press.

Singleton, Jr., R. A., \& Straits, B. C. (2005). Approaches to Social Science Research (Fourth Edition). Oxford University Press.

Smith, S. R., \& Lipsky, M. (1993). Nonprofits for Hire: The Welfare State in the Age of Contracting. Harvard University Press.

Thomas, D. R. (2006). A General Inductive Approach for Analyzing Qualitative Evaluation Data. American Journal of Evaluation, 27(2), 237-246. 


\section{APPENDIX A-1}

\section{ORGANIZATION INTERVIEW GUIDE}


Brief introduction of research goals and aims: This research is being completed to better understand the impact of ride hail services like Uber and Lyft on the ability for individuals to access services provided by nonprofit organizations. You are being asked to participate because you may have opinions about obstacles and opportunities facing nonprofit organizations, and their beneficiaries, in using ride hail services. This is voluntary - you can hang up at any point. Any quotes we may use will not include your name and/or your organization's name.

1) Tell me a little bit about your organization and programs.

2) Does your organization use Uber/Lyft to help clients get to your location and/or other services?

3) How has or does your organization use Uber/Lyft or volunteers for rides?

4) Can you describe how this works for your organization - the logistics?

a. From your perspective, what are the benefits and challenges of ride hail services? For your organization? For your client?

5) How do your clients use these services (that you know of?)

6) What other services have your clients used?

7) How has this landscape changed in the last few months?

a. What do you expect for the future?

b. What have been expressed fears or comforts?

c. Increased/decreased your client use? Demands?

8) What do you expect for ride hail services?

9) Are there communities you have trouble reaching with your transportation supports? Who are they? Why are they difficult to reach and serve?

10) If you would send a message to policymakers, what would it be? Funders?

11) Is there anyone else I should talk to?

12) Would you be willing to allow me to contact your clients? 
APPENDIX A-2

CLIENT INTERVIEW GUIDE 
Brief introduction of research goals and aims: This research is being completed to better understand the impact of ride hail services like Uber and Lyft on the ability for individuals to access services provided by nonprofit organizations. You are being asked to participate because you may have opinions about obstacles and opportunities facing nonprofit organizations, and their beneficiaries, in using ride hail services. This is voluntary - you can hang up at any point. Any quotes we may use will not include your name and/or your organization's name. For your time today, I am offering a $\$ 25$ gift card for either Amazon or Visa.

\section{Ok to Record?}

2. What is your name and where do you live?

3. Tell me about your relationship with Sound Generations.

a. How did you hear about them?

b. Which services do you use?

c. How long have you been using their services?

4. Do you use the VTS program? (Volunteer Transportation Service?).

a. What do you use it for?

b. How frequently do you use them?

c. What do you like most about the program?

d. What are some ways the program might be improved?

5. Do you use other forms of transportation? What do you use?

a. (own car? Rides with friends? Bus? Metro Access? Hopelink? Uber or Lyft?).

b. How frequently do you use these other services (may need to differentiate pre- and post-COVID)

c. What do you use them for?

d. What are some things you like about the different types of services?

e. Could be improved?

6. Specifically, have you ever used Uber or Lyft?

a. Did you pay for it? Did Sound Generations?

b. Have you used it on your own, or only with the help of Sound Generations?

c. How was the experience?

d. What did you like about it, what didn't you like?

7. Have you used Uber and Lyft on your own?

a. Why or why not? 
b. If you said no, are there things uber and Lyft might be able to do to make it easier for you?

8. Anything else you think it is important for policymakers to know about transportation? 


\section{APPENDIX A-3}

\section{INTERVIEW TRANSCRIPT CODING GUIDE}


Ride Hail Services Study: Code Book

\begin{tabular}{|l|l|}
\hline Code & Definition \\
\hline Cost - personal & Refers to cost to client (whether from leader or client) \\
\hline Cost - org & Refers to cost to organization \\
\hline Logistics - personal & $\begin{array}{l}\text { Refers to booking logistics from the client perspective } \\
\text { (whether from leader or client) }\end{array}$ \\
\hline Logistics - org & Refers to booking logistics from the organization \\
\hline Accessibility - disability & $\begin{array}{l}\text { Issues with accessibility for any mode of transportation due } \\
\text { to disability }\end{array}$ \\
\hline $\begin{array}{l}\text { Accessibility - low } \\
\text { income }\end{array}$ & $\begin{array}{l}\text { Issues with accessibility for any mode of transportation due } \\
\text { to income }\end{array}$ \\
\hline Accessibility - App use & $\begin{array}{l}\text { Issues with accessibility for any mode of transportation due } \\
\text { to app use }\end{array}$ \\
\hline Covid Challenge & Challenges associated with travel due to Covid-19 \\
\hline $\begin{array}{l}\text { Covid Benefit or } \\
\text { Opportunity }\end{array}$ & Benefits or opportunities with travel due to Covid-19 \\
\hline Uber/Lyft Challenge & Challenges associated with uber/lyft \\
\hline $\begin{array}{l}\text { Uber/Lyft Benefit or } \\
\text { Opportunity }\end{array}$ & Benefits or opportunities with uber/lyft \\
\hline Bus Challenge & generally same as above \\
\hline $\begin{array}{l}\text { Bus Benefit or } \\
\text { Opportunity }\end{array}$ & generally same as above \\
\hline $\begin{array}{l}\text { Hyde Shuttle } \\
\text { Challenge }\end{array}$ & generally same as above \\
\hline $\begin{array}{l}\text { Hyde Shuttle Ben or } \\
\text { Opportunity }\end{array}$ & generally same as above \\
\hline Vol Drivers Challenge & generally same as above \\
\hline $\begin{array}{l}\text { Vol Drivers Benefit or } \\
\text { Opportunity }\end{array}$ & generally same as above \\
\hline $\begin{array}{l}\text { Access Shuttle } \\
\text { Challenge }\end{array}$ & generally same as above \\
\hline $\begin{array}{l}\text { Access Shuttle Benefit } \\
\text { or Opportunity }\end{array}$ & generally same as above \\
\hline $\begin{array}{l}\text { Independence } \\
\text { (regardless of reason) }\end{array}$ \\
\hline Social Aspect & Refers to comments about one's social life \\
\hline
\end{tabular}

